\title{
Comparative Evaluation of the Four most commonly used Pediatric Liquid Formulations in Ahmedabad City: An in vitro Study
}

${ }^{1}$ Vidhi Shah, ${ }^{2}$ Karthik Venkataraghavan, ${ }^{3}$ Prashant Choudhary, ${ }^{4}$ Krishna Trivedi, ${ }^{5}$ Shalin Shah, ${ }^{6}$ Shilpa Bhandi

\section{ABSTRACT}

Introduction: This study was conducted to assess the cariogenic potential of pediatric liquid medicaments (PLMs) of Allopathic, Homeopathic, Ayurvedic, and Unani formulations specifically in Ahmedabad.

Materials and methods: Four commonly used PLMs were selected based on a survey. Thirty-nine exfoliated deciduous teeth samples were placed in selected PLM for 1 minute, 10 minutes, and 8 hours and observed under scanning electron microscope to check the erosive potential. Their endogenous $\mathrm{pH}$, calcium dissolution potential, viscosity, and type and amount of sugar were checked.

Results: In all the four groups, a specific type of enamel prism pattern was seen in all the samples irrespective of magnification and immersion time. However, the degree of erosion increases with the increase in immersion time. All the four syrups were acidic in nature. Lowest $\mathrm{pH}$ (3.73) and highest calcium dissolution (7.106) were seen in Saduri ${ }^{\circledR}$. Viscosity was higher with Benadry ${ }^{\circledR}$ mainly due to high sugar content (36.10), especially glucose (27.21).

Conclusion: All the PLMs used in this study showed an erosive effect on the primary enamel surface though major effect was seen with Saduri ${ }^{\circledR}$.

Clinical significance: With respect to this study, Unani medications are most cariogenic for the teeth among all the four types of medications in children.

Keywords: Calcium dissolution potential, Erosive potential, Pediatric liquid medicaments, Scanning electron microscope, Viscosity.

How to cite this article: Shah V, Venkataraghavan K, Choudhary P, Trivedi K, Shah S, Bhandi S. Comparative Evaluation of the Four most commonly used Pediatric Liquid Formulations in Ahmedabad City: An in vitro Study. World J Dent 2017;8(3):190-195.

Source of support: Nil

Conflict of interest: None

1,2,4,5 Department of Pedodontics and Preventive Dentistry College of Dental Sciences \& Research Center, Ahmedabad Gujarat, India

${ }^{3}$ Faculty of Dentistry, SEGi University, Selangor, Malaysia

${ }^{6}$ Department of Restorative Dental Sciences, College of Dentistry, Jazan University, Jazan, Kingdom of Saudi Arabia

Corresponding Author: Karthik Venkataraghavan, Department of Pedodontics and Preventive Dentistry, College of Dental Sciences \& Research Center, Ahmedabad, Gujarat, India Phone: +9198452 58974, e-mail: veekart@yahoo.co.in

\section{INTRODUCTION}

Erosive potential is the ability of a substance to induce or potentiate the formation of dental caries. Dental caries is considered to be one of the most common oral diseases in childhood. ${ }^{1}$

In the Indian scenario, over and above the allopathic medications, the medicaments commonly used over the counter as well as by the doctors are the Homeopathic, Ayurvedic, and Unani preparations. On an average, 65\% of the population is consuming such preparations among which Homeopathy has $40 \%$ and Unani 5\%, whereas Ayurvedic consumption is $20 \%$. The main advantage of these preparations is that they are palatable and sweet in taste and hence, children can consume them easily. Ayurvedic and Unani preparations consist of natural plants and indigenous products, and they are bitter in taste. The major disadvantage is sweetening agents are added which possess cariogenic potential by reducing the plaque $\mathrm{pH}$ and are alcohol-based preparations. No studies have been carried out so far comparing these four formulations or individually to show their effect on teeth.

There is growing concern among pediatric dentists about the increased consumption of "hidden sugars" by children, especially those who are chronically ill. Hence, the purpose of this study was to assess the cariogenic potential of pediatric liquid medicaments (PLMs) of Allopathic, Homeopathic, Ayurvedic, and Unani varieties, specifically in Ahmedabad where all the four varieties are widely used.

\section{MATERIALS AND METHODS}

Pediatric antitussive liquid medicaments of four different formulations selected for this study were Allopathic, Ayurvedic, Unani, and Homeopathic. The syrup was selected based on survey among practitioners in Ahmedabad city (Fig. 1). ${ }^{2}$ Seventy-eight exfoliated or extracted caries, discoloration, or restoration-free deciduous teeth were selected for this study. Only deciduous maxillary anteriors were selected in this study. The teeth were stored after prophylaxis as per the Occupational Safety and Health Administration regulations in normal saline until the tests were performed. 


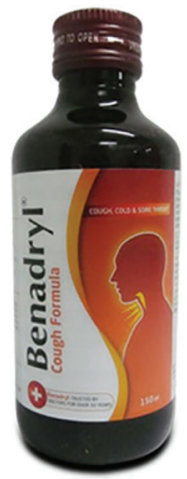

1

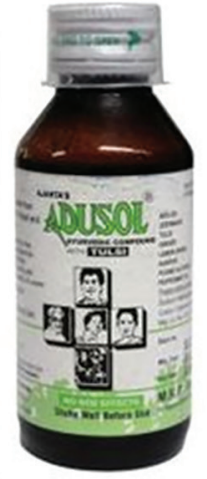

3

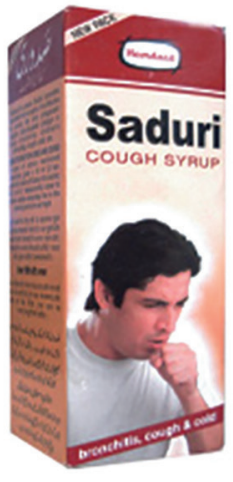

4
Fig. 1: Test groups: (1) Allopathic, (2) Homeopathic, (3) Ayurvedic, (4) Unani

\section{Evaluation of the Surface Changes of Primary Enamel by SEM}

A total of 39 exfoliated deciduous teeth were divided into two groups, i.e., control group (3) and study group (36). The control group samples were placed in artificial saliva for three different time intervals (1 minute, 10 minutes, and 8 hours). The study group samples (36) were maintained for 1 minute, 10 minutes, and 8 hours in various selected PLMs (Fig. 2). The primary enamel surface changes were then observed under scanning electron microscope (SEM; LEO s-440i, UK) (Fig. 3).

\section{Measurement of $\mathrm{pH}$}

Endogenous $\mathrm{pH}$ was measured using digital $\mathrm{pH}$ electrodemeter (Systronics $\mathrm{pH}$ system 361) for the selected PLMs.

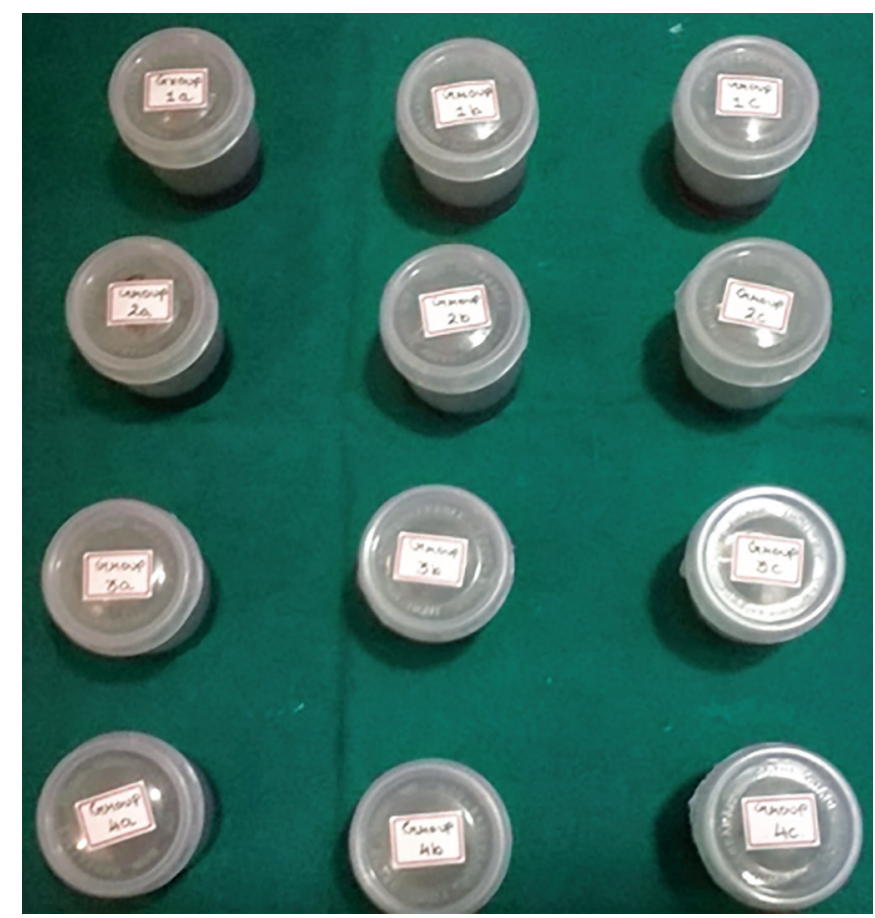

Fig. 2: Sample groups

\section{Estimation of Calcium Dissolution Potential of Syrup from 50 mg of Enamel Powder}

A total of 39 exfoliated primary teeth were used to estimate the calcium dissolution potential (Fig. 4). The internal dentin support was removed using a highspeed dental handpiece. The remaining enamel shell was ground to fine powder by the use of a mortar and pestle, and this powder was used for the study. Fifty milligrams of enamel powder was then mixed with $2 \mathrm{~mL}$ of each medicament. All mixtures were maintained at three different periods of time (1 minute, 10 minutes, and 8 hours). The enamel powder was removed from each sample after centrifugation for 5 minutes at $4000 \mathrm{rpm}$. A $0.5-\mathrm{mL}$ aliquot of each supernatant was removed and placed into a porcelain crucible. The samples were dried at $100^{\circ} \mathrm{C}$ for 2 hours in a hot air oven and ashed in a furnace at $650^{\circ} \mathrm{C}$ for 18 hours. The residue was dissolved in $0.1 \mathrm{~mL}$ of concentrated hydrochloric acid and boiled gently to convert pyrophosphate back to orthophosphate. Distilled water was added to the dissolved ash to make the solution up to $1 \mathrm{~mL}$. Calcium was estimated using atomic absorption spectrophotometer (Perkin Elmer AAS 3100, Germany). The amount of calcium dissolved was calculated by subtracting the calcium concentrations in the mixtures without enamel from calcium concentration mixtures containing powdered enamel.

\section{Measurement of Viscosity, Type and Amount of Sugar in Syrup}

The viscosity of PLM was measured with the help of Ostwald viscometer. Analysis of sugars (glucose, fructose,

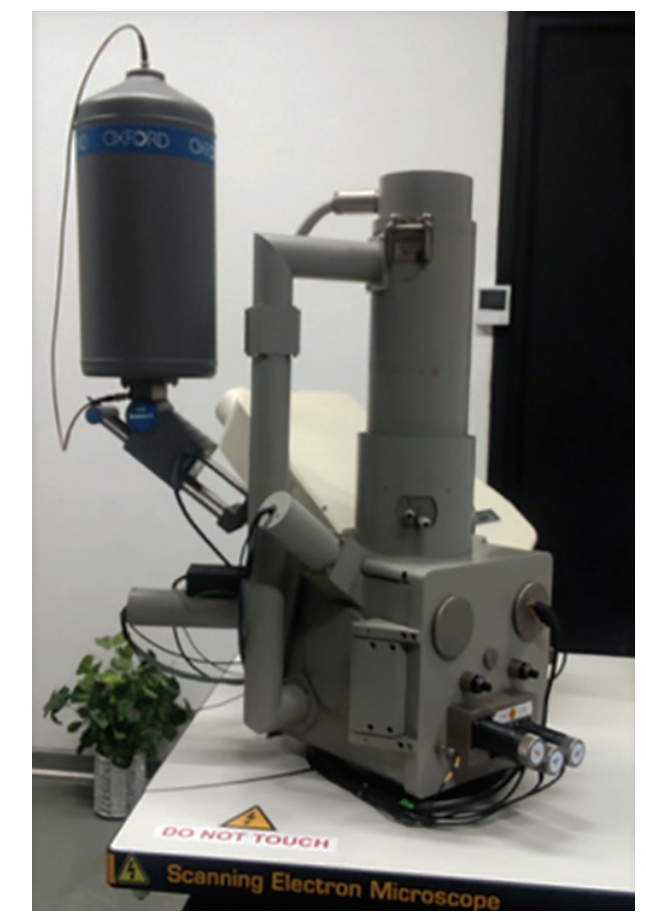

Fig. 3: Scanning electron microscope (LEO s-440i, UK) 


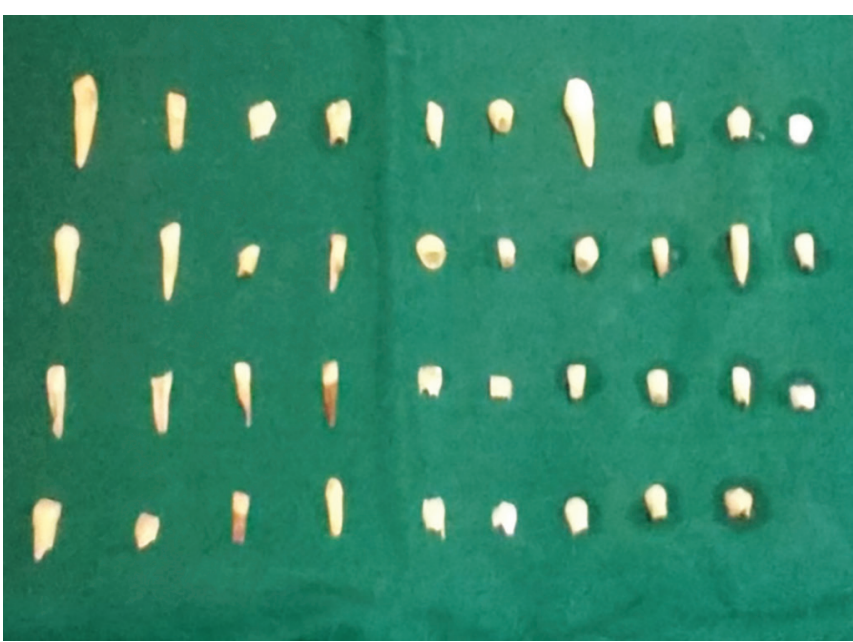

Fig. 4: Samples for estimation of calcium dissolution potential

sucrose, xylitol, and sorbitol) was performed using highperformance liquid chromatography (HPLC; Agilent 1100 system, UK). Five milliliters of each of PLM was pipetted into a $10 \mathrm{~mL}$ of volumetric flask, to which $2 \mathrm{~mL}$ of diluent was added and sonicated for 5 minutes. Microdilutions of $1 \mathrm{~mL}$ were passed through $0.45 \mathrm{~mm}$ filter paper, and supernatant was used for chromatography. All samples were prepared in triplicate.

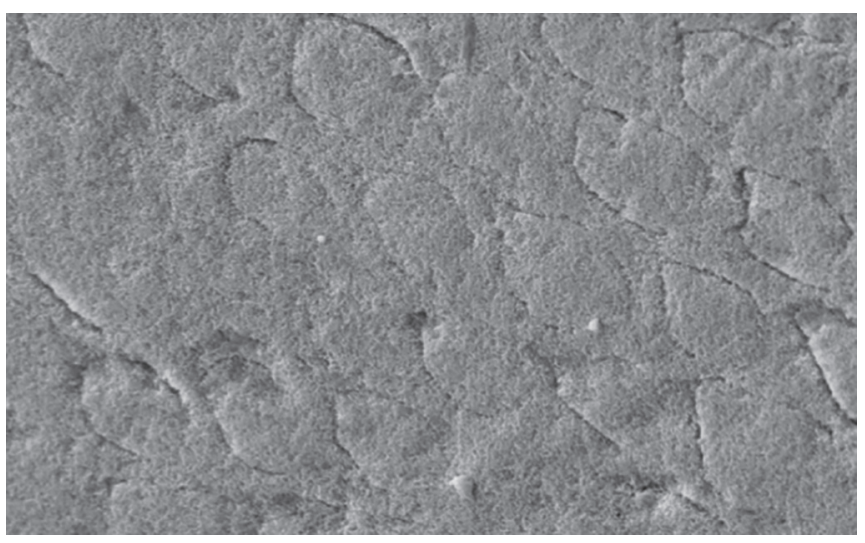

Fig. 5: Scanning electron microscope image for Benadry $l^{\circledR}$ at 8 hours

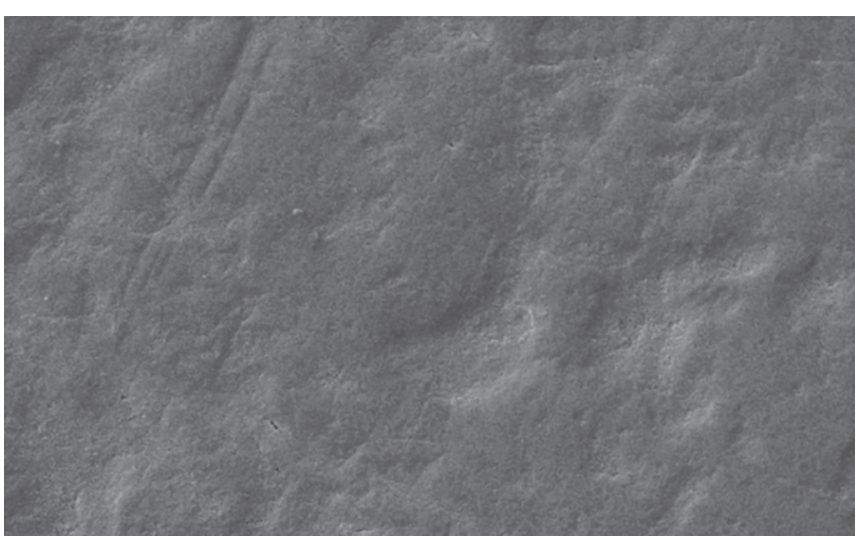

Fig. 7: Scanning electron microscope image for Adusol ${ }^{\circledR}$ at 10 minutes

\section{RESULTS}

\section{Surface Changes of Primary Enamel by SEM}

In all the four study groups, pit-like crater formation was seen on the enamel (Figs 5 to 8). A specific type of enamel prism pattern was seen in all the samples irrespective of magnification and immersion time. However, the degree of erosion increases with the increase in immersion time. Depending on the frequency and size of craters seen on all the samples, it was found that Saduri ${ }^{\circledR}$ syrup had the more erosive tendency.

\section{Measurement of $\mathrm{pH}$}

pH was measured using digital $\mathrm{pHelectrode} \mathrm{meter.} \mathrm{Table} 1$ shows $\mathrm{pH}$ of all the four groups. It was found to be lowest with Saduri ${ }^{\circledR}$ syrup (3.73) and was highest with Stodal ${ }^{\circledR}$ syrup (4.84).

\section{Estimation of Calcium Dissolution Potential of Syrup from $50 \mathrm{mg}$ of Enamel Powder}

Amount of calcium dissolution varied from 7.106 to $5.311 \mu \mathrm{g}$. Table 2 shows the calcium dissolution potential of all the four groups at three different time intervals.

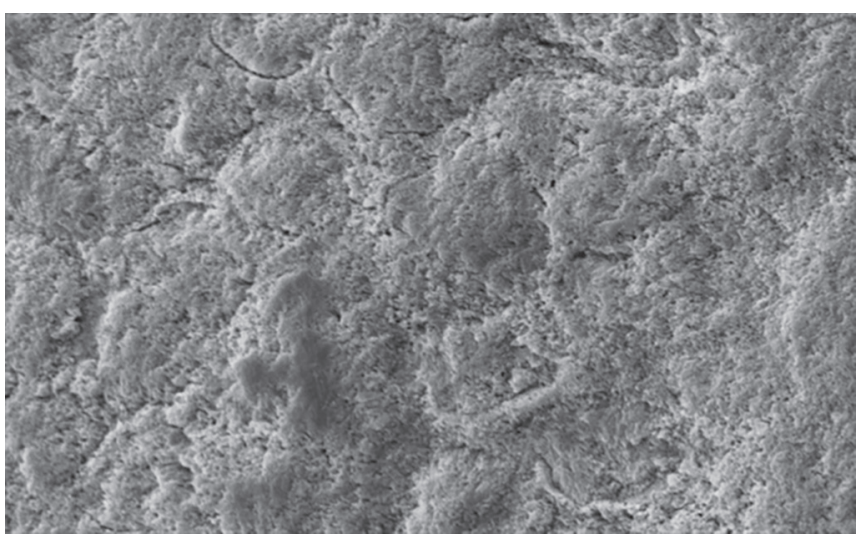

Fig. 6: Scanning electron microscope image for Stodal ${ }^{\circledR}$ at 1 minute

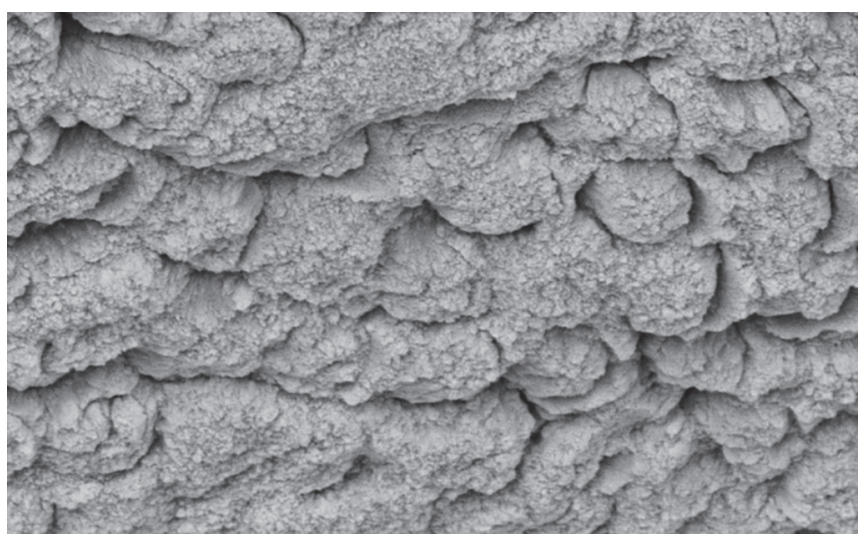

Fig. 8: Scanning electron microscope image for Saduri ${ }^{\circledR}$ at 8 hours 
Table 1: Selected PLMs with their $\mathrm{pH}$, viscosity, and sugar (in \%)

\begin{tabular}{lllll}
\hline Formulation & Brand name & $p H$ & Viscosity & Sugar (in \%) \\
\hline Allopathic & ${\text { Benadry }{ }^{\circledR}}^{\circledR}$ & 4.58 & 84.78 & 36.10 \\
Homeopathic & Stodal $^{\circledR}$ & 3.88 & 4.9 & 27.82 \\
Ayurvedic & Adusol $^{\circledR}$ & 4.84 & 10.6 & 29.47 \\
Unani & Saduri $^{\circledR}$ & 3.73 & 83.81 & 36.38 \\
\hline
\end{tabular}

Highest calcium dissolution was seen with Saduri ${ }^{\circledR}$ syrup, and the least was seen with Benadryl ${ }^{\circledR}$ syrup. When calcium dissolution potential of PLM was compared with their $\mathrm{pH}$, there was statistical significance (Table 3).

\section{Measurement of Viscosity, Type and Amount of Sugar in Syrup}

Table 1 shows viscosity of all the four syrups. Highest viscosity was seen with Benadryl ${ }^{\circledR}$ Syrup $(84.78 \mathrm{cps})$ and lowest was seen with Adusol ${ }^{\circledR}$ Syrup $(4.9$ cps). Tables 1 and 4 show the concentration and type of sugar present in all the four groups respectively.

\section{DISCUSSION}

Based on a survey done in Ahmedabad city, it was found that not only Allopathic formulations but even Homeopathic, Ayurvedic, and Unani formulations were commonly used in pediatric patients, and hence, these formulations were taken into consideration in our study. Hence, being a pedodontist, it is important for us to check their erosive effect on primary teeth.

The erosive effects of this PLM on the primary enamel surface were studied using the SEM. An etching pattern was seen in almost all the enamel specimens. In our study, the majority of the enamel surface looked like large

Table 2: Calcium dissolution potential of all the selected teeth samples at three different time intervals

\begin{tabular}{|c|c|c|c|c|c|c|}
\hline \multirow[b]{2}{*}{ Sample no. } & \multicolumn{3}{|c|}{ Ca present in syrup at } & \multicolumn{3}{|c|}{ Ca dissolution from syrup at } \\
\hline & $1 \min ($ in $\mu g)$ & $10 \min ($ in $\mu g)$ & $8 \mathrm{hr}($ in $\mu g)$ & $1 \min ($ in $\mu g)$ & $10 \min ($ in $\mu g)$ & $8 \mathrm{hr}($ in $\mu g)$ \\
\hline \multicolumn{7}{|l|}{${\text { Benadry }{ }^{\circledR}}^{\circledR}$} \\
\hline 1 & 6.314 & 6.585 & 7.312 & 3.183 & 3.602 & 5.311 \\
\hline 2 & & & & 3.326 & 4.581 & 5.408 \\
\hline 3 & & & & 3.047 & 3.696 & 5.478 \\
\hline \multicolumn{7}{|l|}{ Stodal ${ }^{\circledR}$} \\
\hline 1 & 6.985 & 7.125 & 7.985 & 4.62 & 5.339 & 6.998 \\
\hline 2 & & & & 4.772 & 5.579 & 6.951 \\
\hline 3 & & & & 4.72 & 5.666 & 6.769 \\
\hline \multicolumn{7}{|l|}{ Adusol $^{\circledR}$} \\
\hline 1 & 6.437 & 7.136 & 7.842 & 3.453 & 5.012 & 6.639 \\
\hline 2 & & & & 3.701 & 4.812 & 6.906 \\
\hline 3 & & & & 3.895 & 4.684 & 6.944 \\
\hline \multicolumn{7}{|l|}{ Saduri ${ }^{\circledR}$} \\
\hline 1 & 6.389 & 6.987 & 7.562 & 4.407 & 5.631 & 7.106 \\
\hline 2 & & & & 4.553 & 5.894 & 6.889 \\
\hline 3 & & & & 4.625 & 6.003 & 7.014 \\
\hline
\end{tabular}

Table 3: Comparison of calcium dissolution potential with $\mathrm{pH}$ for statistical significance by ANOVA

\begin{tabular}{|c|c|c|c|c|c|c|c|c|}
\hline $\begin{array}{l}\text { Ca dissolution } \\
\text { from syrup at } \\
(\text { in } \mu g)\end{array}$ & PLMs & $N$ & Mean & $\begin{array}{l}\text { Standard } \\
\text { deviation }\end{array}$ & $\begin{array}{l}\text { Standard } \\
\text { error }\end{array}$ & Minimum & Maximum & $\begin{array}{l}\text { ANOVA } \\
p \text {-value }\end{array}$ \\
\hline \multirow[t]{5}{*}{$1 \mathrm{~min}$} & Benadryl ${ }^{\circledR}$ & 3 & 3.185 & 0.140 & 0.081 & 3.047 & 3.326 & $<0.0001$ \\
\hline & Stodal ${ }^{\circledR}$ & 3 & 4.704 & 0.077 & 0.045 & 4.620 & 4.772 & \\
\hline & Adusol $^{\circledR}$ & 3 & 3.683 & 0.222 & 0.128 & 3.453 & 3.895 & \\
\hline & Saduri ${ }^{\circledR}$ & 3 & 4.528 & 0.111 & 0.064 & 4.407 & 4.625 & \\
\hline & Total & 12 & 4.025 & 0.659 & 0.190 & 3.047 & 4.772 & \\
\hline \multirow[t]{5}{*}{$10 \mathrm{~min}$} & Benadryl ${ }^{\circledR}$ & 3 & 3.960 & 0.540 & 0.312 & 3.602 & 4.581 & 0.001 \\
\hline & Stodal $^{\circledR}$ & 3 & 5.528 & 0.169 & 0.098 & 5.339 & 5.666 & \\
\hline & Adusol $^{\circledR}$ & 3 & 4.836 & 0.165 & 0.095 & 4.684 & 5.012 & \\
\hline & Saduri $^{\circledR}$ & 3 & 5.843 & 0.191 & 0.110 & 5.631 & 6.003 & \\
\hline & Total & 12 & 5.042 & 0.800 & 0.231 & 3.602 & 6.003 & \\
\hline \multirow[t]{5}{*}{$8 \mathrm{hr}$} & Benadryl $^{\circledR}$ & 3 & 5.399 & 0.084 & 0.048 & 5.311 & 5.478 & $<0.0001$ \\
\hline & Stodal ${ }^{\circledR}$ & 3 & 6.906 & 0.121 & 0.070 & 6.769 & 6.998 & \\
\hline & Adusol $^{\circledR}$ & 3 & 6.830 & 0.166 & 0.096 & 6.639 & 6.944 & \\
\hline & Saduri ${ }^{\circledR}$ & 3 & 7.003 & 0.109 & 0.063 & 6.889 & 7.106 & \\
\hline & Total & 12 & 6.534 & 0.696 & 0.201 & 5.311 & 7.106 & \\
\hline
\end{tabular}

ANOVA: Analysis of variance 
Table 4: Analysis of type of sugar (in \%)

\begin{tabular}{llll}
\hline Brand name & Sucrose & Glucose & Sorbitol \\
\hline Benadryl $^{\circledR}$ & 2.75 & 27.21 & 0.89 \\
Stodal $^{\circledR}$ & 0.32 & 3.69 & 24.98 \\
Adusol $^{\circledR}$ & 27.56 & 15.42 & 1.34 \\
Saduri $^{\circledR}$ & 34.84 & 0.84 & 2.89 \\
\hline
\end{tabular}

craters on the microscope. However, the size and depth of these craters varied in almost all the specimens. It was found that the size and number of craters were smaller at 1 minute and increases gradually with the immersion time. Depending on the number and size of craters, highest surface changes were seen with Saduri ${ }^{\circledR}$ and were seen least in Benadryl ${ }^{\circledR}$. The surface changes seen in Adusol ${ }^{\circledR}$ and Stodal ${ }^{\circledR}$ were almost similar; however, they were comparatively lesser than Saduri ${ }^{\circledR}$ Syrup. Silverstone, Saxton, and Dogom described three basic types of etching patterns, i.e., types 1 to $3 .^{3}$ The prism pattern on primary enamel surface observed in our study was similar to type I etching pattern where the prism core material was preferentially removed leaving the prism pattern relatively intact in honeycomb prism appearance, which was similar to results obtained in a study of Babu et al. ${ }^{4}$ Our SEM micrographs showed that the surface was smooth, slightly etched, revealing faint outlines of scale. The enamel rods were clearly opened and the section edge was deep enough to be visible under the SEM. However, the surface topography was found to be of type III etching pattern, generally associated with the aprismatic type of enamel. These results were similar to a study by Grando et $\mathrm{al}^{5}$ who stated that complexity may be seen in different patterns by loss of enamel structure in eroded primary teeth.

All four PLMs studied had acidic $\mathrm{pH}$ below critical level $(<5.5)$ among which Saduri ${ }^{\circledR}$ had the lowest $\mathrm{pH}$ (3.73). Thus, this should be the contributing factor why group 1 showed greater sized craters in SEM compared with other PLM. Studies done by Kiran et al, ${ }^{6}$ Cavalcanti et $\mathrm{al}^{7}{ }^{7}$ Passos et $\mathrm{al},{ }^{8}$ and Babu et $\mathrm{al}^{4}$ had assessed $\mathrm{pH}$ in their respective studies and concluded that PLMs with critically low $\mathrm{pH}$ had the ability to initiate dental demineralization and can cause surface erosion by acting directly on enamel surface. At critical $\mathrm{pH}$, enamel gets unsaturated and sufficiently high concentrations of unionized acid ensure the inward diffusion of enough acid to extend the lesion. ${ }^{9}$

All the medicaments studied showed the calcium dissolution of primary enamel at acidic $\mathrm{pH}$ as all the PLMs had $\mathrm{pH}$ below critical $\mathrm{pH}$ of the oral cavity. Amount of calcium dissolution varied from 7.106 (Saduri ${ }^{\circledR}$ ) to 5.311 (Benadryl ${ }^{\circledR}$ ). In children, the lower concentration of calcium in the whole saliva means that oral $\mathrm{pH}$ does not have to drop as much before demineralization occurs compared with adults. The driving force for demineralization is greater in children than in adults. However, and probably more importantly, the driving force of remineralization is less in children when oral $\mathrm{pH}$ returns to normal. Thus, for children, the lower salivary calcium concentration means a higher critical $\mathrm{pH}$ and a lower driving force for remineralization compared with adults.

To find other factors that may be responsible for erosion in primary teeth in vivo, viscosity and type and concentration of sugar were also measured, which revealed the following: Benadryl ${ }^{\circledR}$ showed highest viscosity $(84.78 \mathrm{cP})$ due to higher sucrose level and Stodal ${ }^{\circledR}$ which contains Sorbitol as a sweetening agent showed least viscosity $(4.9 \mathrm{cP})$ as sorbitol is a sugar substitute and does not contribute to viscosity. The syrups with high viscosity retain on the teeth surface for a longer duration leading to enamel erosion. Liquid medications with low $\mathrm{pH}$ and high viscosity when administered frequently have greater synergistic potential to cause dental erosion. ${ }^{6}$ Liquid preparations are usually sweetened, which are readily fermented by the oral acidogenic bacteria. The medicines that have sucrose as a sweetening agent possess high viscosity. ${ }^{6}$ As a result, these medicines have slow salivary clearance and can cause greater dissolution of enamel.

The sugar content in this study ranged from 27.82 to $36.38 \%$. Barring the sugar-free medicines, Subramaniam and Nandan ${ }^{10}$ observed that the drug labels only provided information on presence or absence of sugars in the syrups medicines, rarely mentioning about the type of sugar present similar to Cavalcanti et $\mathrm{al}^{7}$ in 2001. In this study, HPLC enables the discrimination of individual sugars present in syrup as well as its concentration with remarkable accuracy. ${ }^{11}$

The selection of sugars for analysis was based on the frequency of their inclusion in PLM. Sucrose, followed by glucose, is the commonly added bulking and sweetening agents present in almost all PLM. Fructose is not used frequently in most preparations. Among the sugar substitutes, sorbitol is commonly used. In the present study, three of four PLMs had glucose ranging from 0.84 to 27.21 $\mathrm{gm} \%$, whereas sucrose was found in all the four PLMs ranging from 0.32 to $34.84 \mathrm{gm} \%$. In our study, sorbitol was detected in all four PLMs ranging from 0.89 to 24.98 $\mathrm{gm} \%$. This was in accordance with reports on PLM in Cavalcanti et $\mathrm{al}^{12}$ and Neves et al. ${ }^{2}$

Since the erosion in this experiment was induced under in vitro conditions, it was clear that the results are not completely transferable in vivo. The presence of pellicle would protect the teeth from acidic challenges. It has also been suggested that the amount and quality saliva, in particular its buffering capacity, are important in the occurrence of dental caries. It has been shown that the 
children between 3 and 7 years have larger variations and slower salivary sugar clearances and also lower salivary flow rates than older children and adults.

The percentage of pediatric medicines with sucrose in their compositions varies from 0 to $58.30 .{ }^{13}$ Pomarico et $\mathrm{al}^{14}$ reported that sucrose present in 7 of 10 samples studied ranged between 5 and $54 \mathrm{gm} \%$. Another study detected sucrose in 10 of 23 samples investigated with concentrations ranging from 11.36 to $85.99 \mathrm{gm} \%{ }^{13}$ The other sugar that has been most commonly identified in pediatric medicines is glucose. Pierro et $\mathrm{al}^{11}$ have reported the presence of glucose in several PLM, with the range varying between 2.10 and $40.19 \mathrm{gm} \%{ }^{13,14}$

This study shows that all PLMs can cause erosion and more erosive potential is seen in Saduri ${ }^{\circledR}$, but this needs to be further evaluated in vivo. On evaluation of literature related to PLM, it was found that till now no studies have been carried out to evaluate the erosive potential of PLM other than allopathic formulation. In addition to in vitro studies of other formulations, several in vivo studies need to be carried out to check for its erosive potential.

\section{CONCLUSION}

From this study, it can be concluded that demineralization potential is greatest in Saduri ${ }^{\circledR}$ followed by Adusol ${ }^{\circledR}$, Stodal ${ }^{\circledR}$, and least in Benadryl ${ }^{\circledR}$.

\section{REFERENCES}

1. Menezes V, Cavalcanti G, Mora C, Garcia AF, Barbosa R. Pediatric medicines and their relationship to dental caries. Braz J Pharm Sci 2010 Jan-Mar;46(1):157-164.

2. Neves BG, Pierro VS, Maia LC. Pediatricians' perceptions of the use of sweetened medications related to oral health. J Clin Pediatr Dent 2008 Winter;32(2):133-137.

3. Silverstone LM, Saxton CA, Dogon IL, Fejerskov O. Variation in the pattern of acid etching of human dental enamel examined by scanning electron microscopy. Caries Res 1975;9(5)373-387.

4. Babu KL, Rai K, Hedge AM. Pediatric liquid medicaments - do they erode the teeth surface? An in vitro study: Part I. J Clin Pediatr Dent 2008 Spring;32(3):189-194.

5. Grando LJ, Tames DR, Cardoso AC, Gabilan NH. In vitro study of enamel erosion caused by soft drinks and lemon juice in deciduous teeth analysed by stereomicroscopy and scanning electron microscopy. Caries Res 1996;30(5):373-378.

6. Kiran K, Vinay C, Uloopi KS, Chandra Shekhar R, Madhri V, Alla R. Erosive potential of medicated syrups on primary teeth: an in-vitro comparative study. Br J Med Med Res 2015;5(4):67-74.

7. Cavalcanti AL, De Sousa RI, Clementino MA, Vieira FF, Cavalcanti CL, Xavier AF. In vitro analysis of the cariogenic and erosive potential of paediatric antitussive liquid oral medications. Tanzan J Health Res 2012 Apr;14(2):139-145.

8. Passos IA, de M Freitas CH, Sampaio FC. Fluoride concentration and $\mathrm{pH}$ of pediatric medicines regularly and long-term used by children. Med Oral Patol Oral Cir Bucal 2011 May 1;16(3):e459-e462.

9. da Silva Pierro VS, Furtado BR, Villardi M. Erosive effect of an antihistamine liquid formulation on bovine teeth: influence of exposure time. Braz J Oral Sci 2010;9(1)20-24.

10. Subramaniam $P$, Nandan N. Cariogenic potential of pediatric liquid medicaments - an in vitro study. J Clin Pediatr Dent 2012 Summer;36(4):357-362.

11. Pierro VS, Abdelnur JP, Maia LC, Trugo LC. Free sugar concentration and $\mathrm{pH}$ of paediatric medicines in Brazil. Community Dent Health 2005 Sep;22(3):180-183.

12. Cavalcanti AL, de Oliveira KF, Xavier AF, Pinto DS, Vieira FF. Evaluation of total soluble solids content (TSSC) and endogenous $\mathrm{pH}$ in antimicrobials of pediatric use. Indian J Dent Res 2013 Jul-Aug;24(4):498-501.

13. Lima KT, Almeida IC, Senna ET. Sweeteners and endogenous $\mathrm{pH}$ of pediatric medicines [Abstract B - 110]. J Dent Res 2000;79:1130.

14. Pomarico L, Czauski G, Portela MB, de Souza IP, Kneipp L, de Araújo Soares RM, de Araújo Castro GF. Cariogenic and erosive potential of the medication used by HIV-infected children: $\mathrm{PH}$ and sugar concentration. Community Dent Health 2008 Sep;25(3):170-172. 